\title{
La representación de indígenas y afrodescendientes en la fotografía antropológica en Brasil
}

\section{The representation of indigenous and Afro-descendants in anthropological photography in Brazil}

\author{
Michelle Moreira \\ Universidad Europea del Atlántico, España \\ michelle.moreira@uneatlantico.es \\ https://orcid.org/oooo-0003-1508-6989
}

\section{Resumen:}

Brasil pasa por una época crítica de su historia social. Sin embargo, puede ser el momento idóneo para repensar el racismo estructural construido por el proceso colonial. A partir de una revisión histórica de la representación de indígenas y afrobrasileños en la fotografía antropológica brasileña, se buscó reconocer la evolución del discurso colonial desarrollado en el país. El estudio se apoyó en una consulta amplia de fotografías emblemáticas de archivos públicos y privados, y la lectura de antropólogos e historiadores. Se proponen cinco fases de esta genealogía de la colonialidad en el país a partir de esta revisión. En la actualidad, se perciben prácticas que buscan descolonizar a partir de una relectura crítica y dialógica de la memoria fotográfica que pueda curar y transformar simbólicamente la identidad de los grupos violados por la historia colonial, pero un nuevo desafío se interpone a partir de los algoritmos informáticos.

\begin{abstract}
:
Brazil is going through a critical moment in its social history. However, it may be the appropriate time to rethink the structural racism built by the colonial process. Based on a historical review of the representation of indigenous and AfroBrazilian people in Brazilian anthropological photography, we sought to recognize the evolution of the colonial discourse developed in the country. The study was supported by a broad research on emblematic photographs from public and private archives, and the reading of anthropologists and historians, especially Fernando de Tacca (2011). Five phases of this genealogy of coloniality in the country are concluded from this review. Currently, practices that seek to decolonize are perceived from a critical and dialogical rereading of photographic memory that can heal and symbolically transform the identity of the groups violated by colonial history, but a new challenge is interposed from the computer algorithms.
\end{abstract}

Palabras clave: fotografía; antropología; racismo; colonialidad; Brasil

Keywords: Photography; Anthropology; Racism; Coloniality; Brazil 


\section{La representación de indígenas y afrodescendientes en la fotografía brasileña antropológica desde una perspectiva histórica crítica}

Hay una historia visual que se repite en muchos países de América Latina: la representación fotográfica de indígenas y afroamericanos por fotógrafos europeos. Esta narrativa acompaña el proceso histórico colonial vivido por la región y el desarrollo de la antropología como ciencia.

Nos interesa remarcar, desde una perspectiva histórica, el desarrollo de una genealogía de la colonialidad a partir de la representación de estos dos pueblos, indígenas y africanos, en el contexto de la antropología en Brasil, a través de un corpus fotográfico que ha sido referencia en las fotografías antropológicas brasileñas. Estas fotografías, hoy disponibles en acervos fotográficos públicos y privados, algunos también accesibles virtualmente, nos cuentan más de lo que podemos visualizar en las imágenes. Las fotografías requieren un análisis del contexto para comprender mejor su producción y difusión como bienes de interés público, como información y patrimonio.

Aquí nos apoyamos en Ariella Azoulay (2008 y 2012), quien nos cobra un posicionamiento socialmente comprometido como lectores de fotografías, a partir de lo que la autora define como "contrato social". Es esta responsabilidad, que va más allá de la percepción estética de la obra para profundizar en la significación social y política, la que nos hace revisar los archivos para comprender su mensaje y función en el aparato discursivo de una época. En este proceso historicista, buscar leer las imágenes, además del "qué" y "cómo" se hicieron las fotografías, requiere pensar en el "por qué" para comprender las narrativas dominantes del discurso imperativo.

Nos centraremos en un tema actual que toma cada vez más relevancia, a partir del concepto de la colonialidad, elaborado por el grupo Colonialidad / Modernidad, que ha analizado de manera más profunda el sistema colonial creado en las Américas como un proceso de dominación que se basa, entre otros aspectos, en la diferenciación racial y la construcción del racismo.

En el contexto específico brasileño, dialogar con estas fotografías desde esta perspectiva histórica crítica es una posibilidad de retomar lo que Paulo Freire nos 
ha orientado pedagógicamente, es decir, tomar las fotografías como un proceso de comunicación dialógico, en que el medio y el mensaje se reconstruyen a partir del aporte comunitario para un aprendizaje revolucionario, emancipador. Para esto, es necesario un ejercicio de mirar hacia nuevas representaciones, que, además de releer y repensar esta representación de indígenas y africanos en la fotografía antropológica brasileña -o deconstruir el racismo-, permiten también reconstruir nuevas narrativas, que son posibles estrategias para la descolonización.

\section{Descolonizar las imágenes}

En la historia de la fotografía que se suele contar, la invención de la técnica de fijar la luz en el material a través de un proceso físico-químico es considerada como un marco inicial de la práctica fotográfica, olvidándose todo el proceso pictórico que precede y permite la creación de una cultura fotográfica (Azoulay, 2008). Tal visión quita la relevancia de la historia pictórica que antecede la fotografía y que también contribuye para su desarrollo. Un ejemplo son los retratos pintados que se desarrollan en Europa en el siglo XVIII, que reflejan y colaboran para la idea de individualismo y la construcción de la sociedad moderna. Estos pintores, que tenían con el pincel las posibilidades de definir a una persona en un marco, buscaban retratar desde los sujetos más comunes hasta los más ilustres y renombrados personajes sociales, a partir de la elección de colores, posición corporal, proporción física, uso de accesorios, elección del entorno y tamaño de la pintura, entre otros recursos.

Un tipo de discurso visual que pertenece a la imagen civil y que se convirtió en obra representativa del siglo XVIII fue el retrato. En este cada objeto, pose y expresión significan, nada es arbitrario y permite observar los espacios privados del personaje (Badillo, 2018, p. 53).

La pintura retratista contribuyó en la construcción de imaginarios que llevaron a identificar al sujeto según su representación pictórica. Estos imaginarios eran validados por las instituciones, como el Estado y la Iglesia. 
Con la fotografía, sin embargo, con el rechazo a su valor artístico, la observación sobre el acto fotográfico y sus elementos persuasivos ha sido más escasa en la literatura académica del siglo XX. Por el contrario, considerado como registro del real y de la historia, la fotografía ha sido usada como un documento (Pinney, 2016).

En las décadas más recientes, muchos autores han colaborado para que se produjera un cambio de perspectiva. Entre estos, el británico John Tagg, especialmente con sus obras The Burden of Representation: Essays on Photographies and Histories, publicado primeramente en 1988, y The Disciplinary Frame: Photographic Truths and the Capture of Meaning, de 2009. Su contribución es resultado del "giro pictórico" o "giro visual” (Mitchell, 2003, 2009), que influenció los estudios visuales en los años noventa, y ocasionó diversos desdoblamientos, especialmente sobre la interpretación representativa de la cultura visual. Esta "visión socializada" (Mitchell, 2003) ve entre la fisiología de la mirada y el objeto de observación una relación cargada de discursos incorporados que deben ser investigados a través de las prácticas culturales. El interés analítico vincula, a partir de estos nuevos enfoques, las formas a los roles sociales. Mitchell refuerza la importancia de estas imágenes como agentes sociales capaces de producir diálogos y la transformación de los índices en signos posibles de interpretación. Autores como el filósofo francés Louis Althusser, el crítico y fotógrafo británico Víctor Burgin y el fotógrafo y teórico norteamericano Allan Sekula también han colaborado en desarrollar una teoría de la fotografía como práctica de representación que construye significados y realidades (Batchen, 1999).

Conviene resaltar al historiador de arte Hans Belting, que destaca la capacidad de migración de la imagen entre los media, que desvirtúa de su sentido esencial. De esta manera, es más fácil manipular los discursos y dificultar la comprensión de que las imágenes se prestan al uso político: "La representación está destinada sin ninguna duda a gobernar sobre la percepción” (Belting, 2015, p. 161). En la perspectiva de Belting, comprender la historia de las técnicas simbólicas que crean imágenes es comprender las prácticas simbólicas, “a las que llamamos 
percepciones en el sentido de su comportamiento cultural colectivo" (Belting, 2007, p. 63).

Con un enfoque también ontológico, el filósofo Vilém Flusser analizó diversos aspectos políticos y antropológicos para una filosofía de la fotografía. En su análisis, "las imágenes fotográficas significan conceptos en un programa y que programan la sociedad para un comportamiento mágico secundario" (Flusser, 2014, p. 45). Sin embargo, la solución podría estar en reconocer el programa: "son las fotos las que nos someten a un tratamiento, programándonos para un comportamiento ritual al servicio de un feedback en beneficio de los aparatos". Y continúa: "las fotos conforman un círculo mágico que nos rodea en la forma del universo fotográfico. Este círculo es el que hay que romper" (Flusser, 2014, p.67). La fotografía deja de ser un objeto de análisis para convertirse en un campo amplio de estudio sobre sus relaciones con áreas y prácticas diversas. Sin embargo, aunque en los medios académicos o curatoriales esta práctica se ha extendido en la última década, todavía entre el público se puede decir que hay una demanda de alfabetización visual que permita el desarrollo de habilidades de creación y lectura de las fotografías para una comprensión de su sentido más allá de las intenciones del fotógrafo y de la mediación. De este modo, el archivo fotográfico tiene el potencial de dialogar con el pasado y con el presente, y el creador y lector fotográfico, ser un ciudadano autónomo capaz de pensar, analizar y contextualizar la imagen. Azoulay (2008) lo define como esfera política civil, en la que nosotros debemos indagar sobre las historias que nos cuentan y "asistir" a lo que pasa en la fotografía para entenderla. En esta relación con el espacio público, que no se limita a los espacios académicos y curatoriales, la teoría de Azoulay consigue enfocar la fotografía como agente de apropiación cultural y transformación social.

El documentalismo como práctica fotográfica y el archivo fotográfico como objeto de lectura dejan de ser solamente discursos institucionalizados para convertirse en posibilidad de cura al integrarlos en campos más vastos de actuación. Como afirma Marta Dahó (2015, p.223), "la reevaluación que lleva a cabo Azoulay plantea una comprensión de la fotografía en términos de encuentro colectivo”. 
Además de estas aportaciones, nos interesa especialmente el abordaje postcolonialista que trata la autora israelí, como referencia, aunque nuestro contexto sea diferente. Aquí, este enfoque se dirige especialmente a la evolución de la fotografía con la antropología, ya que ambas coinciden en el tiempo, y son disciplinas asociadas al colonialismo por permitir avanzar un pensamiento y estética imperial sobre los pueblos no europeos. A partir de la curiosidad por el otro, se va permitir el desarrollo de ambas disciplinas, que se apoyan incluso mutuamente (Pinney, 1996).

En la obra editada por Juan Naranjo (2006), Fotografía, antropología y colonialismo (1845-2006), la recopilación de textos históricos nos ayuda a entender esta relación recíproca entre la fotografía y la antropología, y nos propone repensar todas estas políticas de representación de la cultura visual occidental.

Antes, en 1992, la antropóloga británica Elizabeth Edwards editó artículos, en la obra Anthropology and photography (1860-1920), para identificar las evidencias de cómo la fotografía ha servido de instrumento para la creación de contenido etnográfico capaz de dar respuestas a problemas de interpretación en el desarrollo de la antropología. Esta relación entre la fotografía y la antropología ha permitido la "construcción de un discurso coherente sobre la alteridad" (López, 2010, p. 7) a través de las narrativas elaboradas por fotógrafos acompañados de etnógrafos, o etnógrafos que se instrumentaban de cámaras fotográficas.

Aunque en la pintura ya se podría ver las semillas de esta representación exótica sobre el otro -como ejemplo, las ilustraciones realizadas durante las expediciones, como los holandeses Frans Post y Albert Eckhout, que documentaban en las pinturas la formación de la colonia holandesa en Brasil, pintando, además del paisaje natural, la vida de los indígenas y africanos en aquella región entre los años 1637 y 1644- fue la fotografía el instrumento idóneo para la antropología.

La técnica fotográfica permitía, además de un registro más rápido y más realista, reforzar el positivismo científico. Con el desarrollo de la antropología, apoyada 
en notas de campo y fotografías, fue posible estructurar la idea de las razas que hoy marca la sociedad brasileña.

Para analizar esta manera de percibir el mundo que se instaura eliminando otras maneras de percepción, nos apoyamos en los conceptos elaborados por el grupo Modernidad/Colonialidad, con una crítica al eurocentrismo desde la perspectiva latinoamericana.

A partir de Quijano, entendemos la colonialidad como un concepto adecuado para analizar las relaciones de poder establecidas a partir de la clasificación del mundo en razas, la dominación y una colonización cognitiva que permite la hegemonía de la cultura europea.

La Modernidad no solo ha implicado la explotación de las colonias, sino también una narrativa, una ciencia, que justificaba esa explotación de la periferia y se hizo, además de una narrativa, una retórica; es decir, daba argumentos que convencían al contrario (Dussel, 2018, p. 19).

Pero analizamos el pasado para hablar del futuro. Esta crítica epistemológica es importante para un cambio en nuestra práctica académica y fotográfica, para que pueda generar conocimiento que colabore para reparar estas construcciones simbólicas. No se trata de anular la historia colonial, sino de reformar a partir de nuevas visibilidades, reconocer los daños y reconstruir nuevos significados y espacios simbólicos. Para esto se necesita reconocer el sujeto desde esta perspectiva histórica. En este sentido, hablamos en primer lugar de una “descolonización del ser" que nos permita pensar nuestra condición de estar en el mundo de una manera libre de la imposición del racismo.

\section{Brasil, país laboratorio}

En Brasil, por la historia y la confluencia de culturas durante el proceso colonial, podemos observar un espacio de luchas frecuentes entre los grupos sociales que buscan romper con el pensamiento colonial. Esta lucha en general viene de los propios grupos indígenas y afrobrasileños que cobran una reparación por las desigualdades del sistema impuesto a sus cuerpos, memorias y oportunidades de vida. 
Por un lado, la élite se esfuerza en mantener el sistema colonial a partir de un aparato discriminatorio, punitivo y liberal. Por otro lado, hay diferentes formas de redefinir el mestizaje brasileño: indígenas, africanos, mamelucos, caboclos, mulatos, etc.

En este proceso, la fotografía y la antropología han sido claves para definir las diferencias entre las razas. Antropólogos europeos buscaban el país como laboratorio para ampliar los conocimientos sobre la humanidad y sus formas de organizar y pensar el mundo. El interés científico por Brasil, en grande parte por sus naciones indígenas y comunidades afrodescendientes, su diversidad ambiental y por las relaciones coloniales que se establecían, ha colaborado en atraer científicos europeos que marcaron el proceso civilizatorio brasileño.

En este estudio se busca repensar estas relaciones a partir de un corpus fotográfico para entender cómo algunas imágenes, aunque no definitivas, pero sí alegóricas, nos indican epistemologías de diferentes épocas a lo largo de la historia de la antropología en el país y la lectura semiótica de algunas fotografías.

Además, con esta genealogía de la colonialidad en Brasil, se percibe la evolución de estas relaciones de alteridad, establecidas desde la perspectiva eurocéntrica, para finalizar en un proceso que busca descolonizar las miradas, los pensamientos y el "ser” en el país.

\section{Del daguerrotipo a las redes sociales: cambios epistemológicos, perspectivas que se transforman}

A partir de lo que propone Fernando de Tacca (2011), podemos inferir que en la historia de la fotografía antropológica de Brasil ha habido tres momentos diferentes en la representación de las comunidades indígenas.

Tacca establece como primer momento las fotografías positivistas que buscaban trazar rasgos físicos para diferenciarlos con otras razas. En esta época, la antropología se desarrolla a partir de estudios más físicos.

La primera fotografía de un indígena de la que se tiene conocimiento fue tomada en 1844, en la Academia de Ciencias de París, con representantes de la familia 
Macro-Jê (Morel, 2001; Tacca, 2011). El título de esta serie de daguerrotipos indica la falta de conocimiento sobre quien es la persona fotografiada: "Botocudos", que se refiere a la manera como llamaban los colonizadores a los indígenas que usaban botoques en los labios y las orejas. No se conocen sus historias personales, excepto que habían sido capturados y llevados a París para ser estudiados y clasificados.

De manera similar, podemos ver el mismo tipo de representación positivista de los africanos y afrodescendientes en Brasil dos décadas después. En este caso, un trabajo ejemplar de fotografía antropométrica es desarrollado por Auguste Stahl, en 1865, en que se puede ver daguerrotipos de personas de frente y de perfil, con torsos desnudos, acompañadas muchas veces de reglas de medición para ayudar a las clasificaciones raciales. El trabajo desarrollado por el fotógrafo Auguste Stahl, que llegó a Recife en 1853, fue encomendado por el naturalista Louis Agassiz, que tenía interés en conocer la procedencia de diversos africanos que residían en el país para investigar el estudio de las razas. Estas fotografías no nos cuentan sus historias de vida, aunque en las imágenes se pueden ver cicatrices tribales o miradas vacías, de desagrado. Estas imágenes han servido para trazar posibles orígenes africanos en la sociedad brasileña que se formaba desde la identificación de trazos físicos y marcas. Están invisibles en estas imágenes cualquier simbología de resistencia, práctica cultural o hábito organizativo de la vida personal de los fotografiados. No se conocen las relaciones establecidas entre el fotógrafo y los fotografiados, pero, por su condición de esclavitud, se deduce que han sido fotografiados casi sin su consentimiento.

Si analizamos el relato de Elisabeth C. Agassiz y Louis Agassiz, en A journey in Brazil, de 1868, percibimos como en algunos casos, acompañados del fotógrafo Walter Hunnewell, han tenido que convencer los fotografiados para poder tomar sus retratos. La fotografía parece, en el relato, un instrumento de violencia para indígenas y afrodescendientes:

La principal dificultad deriva de los prejuicios de la gente. Entre los indios y los negros está muy extendida la superstición de que los retratos absorben algo de la vitalidad del modelo y que uno tiene más posibilidades de morir después de que le 
hayan sacado un retrato. Esta idea está tan profundamente arraigada que no ha sido nada fácil vencerla (Agassiz \& Agassiz, en Naranjo, 2006, p. 41).

Hunnewell realizó fotografías de entre cincuenta y sesenta habitantes de Manaos durante la expedición que acompañaba a los Agassiz. Estas fotografías tenían como intención ilustrar las razas existentes en Brasil.

En ese momento, el modelo epistemológico dominante era el evolucionismo que buscó argumentar la supuesta diferencia de razas a partir de teorías evolucionistas biológicas, asociando esta "naturalidad" a aspectos culturales y sociales. El comienzo de la antropología tomó como préstamo algunas metodologías propias de las ciencias biológicas, como son la observación, las notas y la clasificación (Edwards, 1996). En esta época, los antropólogos todavía no hacían trabajos de campo de tipo etnográfico y usaban datos recogidos por “colaboradores" para examinar y clasificarlos en las oficinas. De este modo, estas fotografías eran consideradas importantes aliadas para el desarrollo de la ciencia ya que eran fuentes de información para un estudio científico sobre las razas.

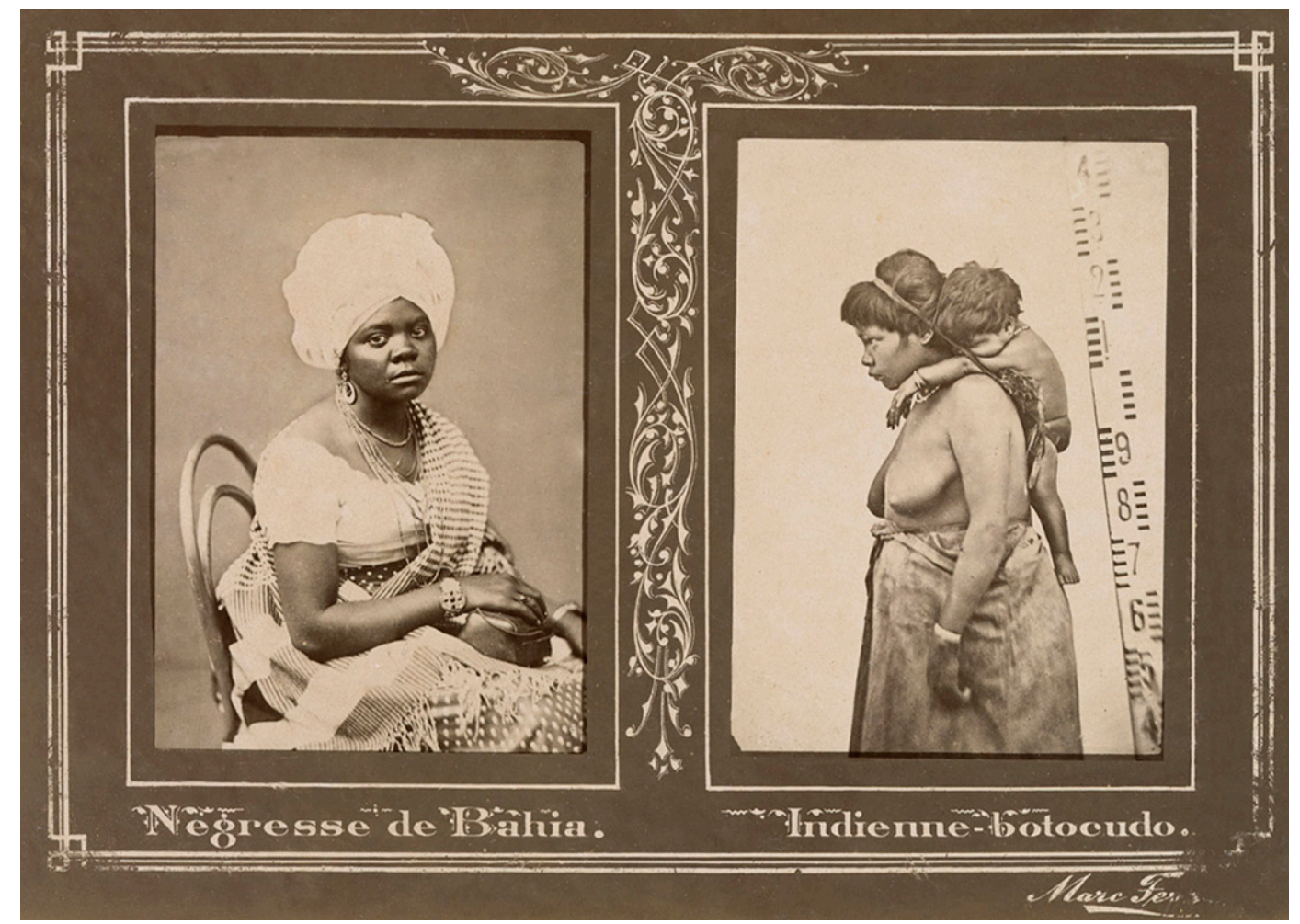

F1. Negra da Bahia e Índia Botocudo, Marc Ferrez.c.1885 Acervo Instituto Moreira Salles 
El interés antropológico, no meramente científico, pero propio de la modernidad, también ha colaborado para la representación exótica de indígenas y africanos en Brasil, que, durante finales del siglo XIX, se caracteriza en los cartes-de-visite o tarjetas postales. Aunque su uso inicial estaba dirigido a fotografiar personas que se interesaban por tener una foto personal como tarjeta de visita, esta práctica se transformó en postales destinados a viajantes extranjeros que visitaban el país. Fotógrafos como Christiano Junior, portugués, instalado en Brasil en 1855, y Marc Ferrez, brasileño hijo de franceses que vivían en el país, desarrollaron retratos hechos en estudios como una oportunidad comercial.

Los viajantes que iban y venían, principalmente de Europa, llevaban como recuerdo la imagen de pueblos exóticos que habitaban Brasil, como una especie de marca de un tropicalismo étnico que se extenderá durante mucho tiempo sobre la identidad del país.

Otra práctica de la época que ha contribuido para las fotografías coloniales en Brasil ha sido la participación del país en las Exposiciones Universales, entre los años 1862 y 1889. Estos eventos, que ocurrían en diferentes ciudades del mundo, colaboraron para la construcción de una identidad nacional direccionada al exterior. Para participar de estas ferias, los fotógrafos buscaban retratar estos pueblos como un atractivo de interés que servían como una oportunidad de destaque profesional. Las exposiciones fueron espacios importantes en la estructuración del racismo brasileño porque para cada participación brasileña, la élite del país planeaba con antelación cómo se debería promocionar la imagen de la nación (Schuster y Buenaventura, 2017). Esto se refería principalmente a la representación de indígenas, afrodescendientes y blancos.

En esta época destaca también la obra del fotógrafo Marc Ferrez, que nació en Río de Janeiro y estudió en París hasta los 18 años, para luego regresar a Brasil. Su obra es una referencia importante ya que, en sus fotografías, hoy preservadas en el acervo del Instituto Moreira Salles, se puede percibir una gran cantidad de imágenes, con muy buena calidad, de africanos y afrodescendientes trabajando en plantaciones de café en una zona geográfica de relevancia política y económica del país. Estas fotografías marcan los cuerpos de los fotografiados con simbologías de trabajo esclavo, un trazo relevante de la imposición de las 
relaciones de poder de la sociedad brasileña de aquella época. Como observó Schwarcz (2013), estas fotografías sobre los cultivos de café nos presentan imágenes de una esclavitud estable, ordenada y pacífica, sin trazos de resistencia o violencia.

Por el lado indígena, Tacca (2011) destaca sobre los trabajos de Marc Ferrez la intención de domesticar al salvaje al llevarlos de su lugar a un estudio fotográfico en que se escenifican pose, ambiente y aderezos.

En estas representaciones de Ferrez, se ve una tipificación del indígena idealizada y romantizada, casi una alegoría. Por otro lado, los afrodescendientes, libres o esclavos, han sido representados asociándolos a su papel productivo en el sistema local, en muchas imágenes, en posiciones subalternas. Estas imágenes no representan ningún elemento de desorden, de lucha, de confronto social. Son, en ambos casos, auténticos ejemplos de fotografías coloniales.

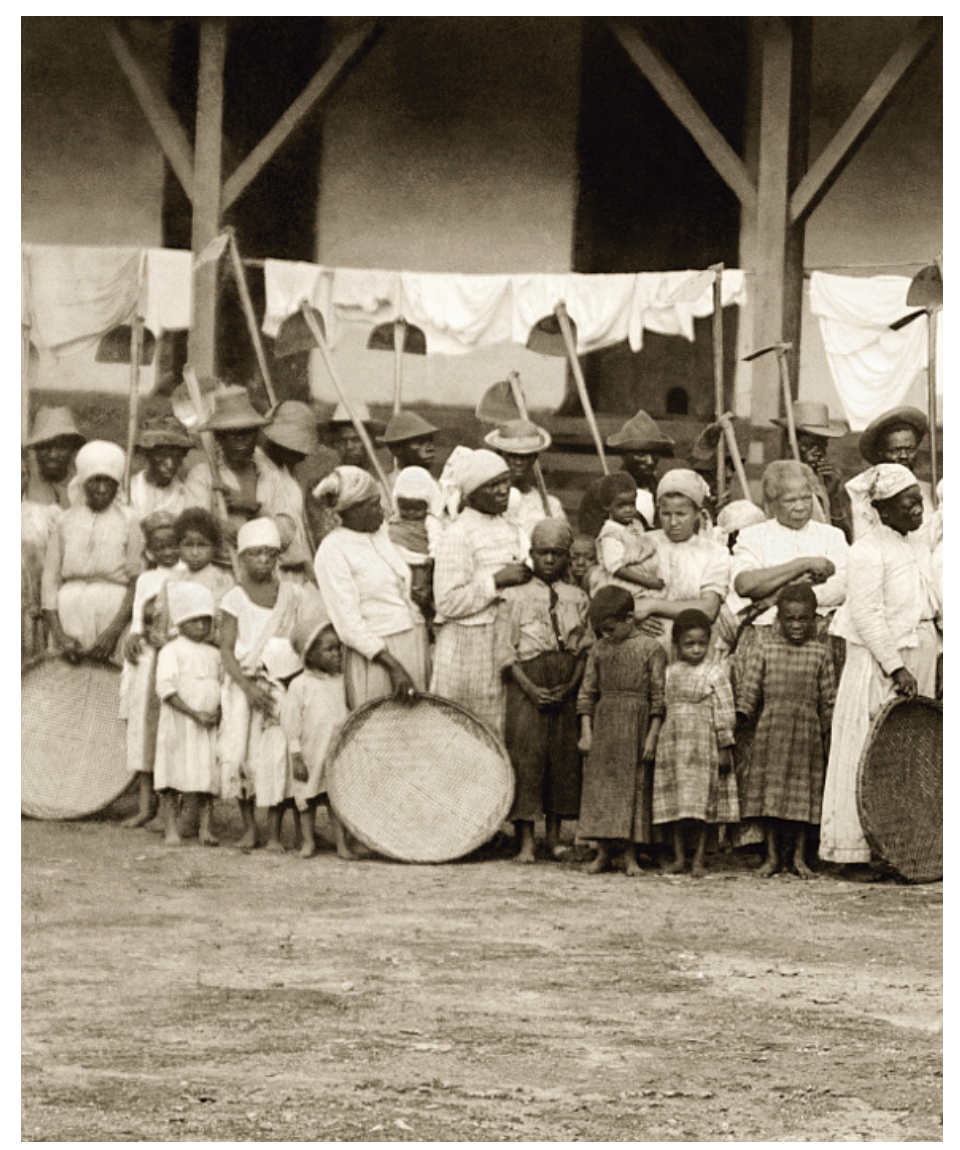

F2. Partida para colheita do café | Vale do Paraíba, c. 1885. Marc Ferrez. Acervo Instituto Moreira. 
A finales del siglo XIX, se percibe una presión social por el fin de la esclavitud y una protección mayor a las comunidades indígenas. Este movimiento internacional puede haber provocado un cambio cada vez mayor de la visibilidad de indígenas y afrodescendientes en las fotografías presentes en las Exposiciones Universales, que pasan a exhibir más imágenes de inmigrantes europeos que vienen al país para ocupar puestos de trabajo. La idea de progreso exigía un cambio también en estas representaciones.

Se desarrolla una segunda fase que va cambiando lentamente el discurso. En el caso de las comunidades indígenas, estos cambios se perciben, como comenta Tacca (2011), a partir de expediciones como la Comisión Rondón, expedición iniciada en 1890, formada por diversos científicos que buscaron sistematizar la vida de los grupos indígenas.

Este momento marca una fase de transición entre el periodo positivista y un periodo etnográfico, con estudios de campo acompañados por fotografías. Se crea el Servicio de Protección a los Indígenas en 1910, primera institución creada para tratar cuestiones indígenas. Es una época en que el país busca definirse como nación moderna, a partir de la noción de integración social. En este periodo, se desarrolla la teoría de la democracia racial y del blanqueamiento de la población brasileña, resultado del mestizaje y de la colonización de inmigrantes europeos.

El momento, sin embargo, aún demuestra una dificultad de relación entre los grupos, y el interés explícito del Estado en domesticar y pacificar a los indígenas, integrándolos en la sociedad brasileña. Es curioso cómo, al ver las fotografías de la expedición Rondón, se perciben las relaciones entre los blancos y los indígenas, vistas por primera vez en la fotografía (Viveiros de Castro, 2011). Hasta entonces, las imágenes, en su mayoría, representaban indígenas aislados, algunos en estudio, otros en su hábitat, pero no con otras personas que no fueron indígenas. En las fotografías de la expedición se inicia este proceso de relación que luego se plasmará en las fotografías más etnográficas.

Esta época sembró la transformación de la antropología física, de datos, para una práctica de observación e interpretación sobre el otro. Es un ejemplo brasileño de lo que comenta Pinney (1996) sobre un momento crucial para la emergencia 
del investigador de campo en el desarrollo de la antropología. El cambio se percibe, especialmente en el caso brasileño, en las expediciones de contacto con las comunidades indígenas.

Sobre la cultura afrobrasileña, durante la primera mitad del siglo XX, los estudios antropológicos parecen ser más escasos. De acuerdo con el venezolano Jesús “Chucho” García (2002), las investigaciones sobre la cuestión africana empiezan a desarrollarse más en la academia a partir de los años 1920, desde la antropología con nombres como Nina Rodríguez y Roger Bastide en Brasil.

Durante estas primeras décadas del siglo, en los análisis de algunas de las imágenes más emblemáticas del periodo que se han podido verificar, se ha reproducido la simbología subalterna y laboral de los afrodescendientes, como en las fotos realizadas anteriormente por Christiano Junior, Alberto Henschel, João Goston y Revert Henrique Klumb, que realizan registros fotográficos de personas afrodescendientes en trabajos y servicios en la ciudad.

Quien rompe de manera destacada este sistema de representación es el fotógrafo Pierre Verger a partir de la década de 1940. Su trabajo, al principio desinteresado, toma un corte cada vez más antropológico al buscar conocer las raíces culturales de los afrodescendientes que vivían en Salvador de Bahía, por recomendaciones del antropólogo Roger Bastide (Shirey, 2017). El fotógrafo francés creó una obra de gran importancia, registrando manifestaciones típicas de los afrobrasileños de Bahía, especialmente relacionadas con la cultura y la religiosidad. "A medida que se desarrollaba su práctica fotográfica, Verger buscó plasmar las prácticas culturales de manera sistemática, presentando estas imágenes estratégicamente para complementar el análisis antropológico" (Shirey, 2017, p. 3). ${ }^{1}$

Sus fotografías rompen con las imágenes de las décadas anteriores al resaltar desde la corporalidad la vida de los personajes fotografiados. En sus fotos, estas personas tienen más personalidad a partir del uso de gestos, movimientos

1. Traducción libre de la autora de "As his photographic practice developed, Verger sought to capture the cultural practices in a systematic manner, presenting these images strategically in order to complement anthropological analysis". 
corporales, relación entre las personas, ocupación del territorio y la aproximación a la cámara.

Esta visión sobre los cuerpos negros, aunque también folclórica, abre nuevos caminos para la fotografía antropológica, que coincide con el interés de los antropólogos que entran en el centro del país para conocer más sobre la forma organizativa de las comunidades indígenas.

A partir de los años cuarenta, se desarrollan dinámicas más etnográficas y documentales, como el trabajo de Pierre Verger. En este periodo, tenemos el ejemplo del antropólogo francés Claude Lévi-Strauss, que, durante su estadía en Brasil para inaugurar el programa de Sociología en la Universidad de São Paulo, participó de la Expedición Serra do Norte, junto con el antropólogo brasileño Luiz de Castro Faria. A partir de esta experiencia, Lévi-Strauss publicó el libro Tristes Trópicos (publicado originalmente en Francia en 1955), con imágenes de las tribus Bororo, Kadiwéu, Mundé, Nambikwara y Tupi-Kawahib. En las fotografías del libro, se ve el interés por conocer los sistemas de vida: representaciones corporales, rituales, organizaciones comunitarias, etc.

Durante dos décadas, las fotografías de los pueblos indígenas se desarrollan sobre el interés etnográfico por conocer esta realidad. Diversos fotógrafos, entre fotoperiodistas y antropólogos, visitan con frecuencia las tribus indígenas y van creando un conjunto iconográfico que servirá para estudiar con más profundidad las diversas etnias que vivían aisladas en el país.

Este proceso sigue también las iniciativas del Estado de unificar los territorios para la composición de una nación, registrando de forma más sistemática las formas de vida de estas zonas menos conocidas del país.

Sin duda, la creación del Parque del Xingú por los hermanos Villas-Boas ha sido un marco importante en las relaciones entre la sociedad brasileña y las comunidades indígenas, especialmente por el trabajo exhaustivo de la antropología en representar, sea en fotografías o en vídeos, a los pueblos indígenas. Diversos fotógrafos (entre ellos, muchos europeos) destacaron por sus trabajos con series de fotografías elaboradas en el Parque del Xingú. Como comenta Viveiros de Castro: 
Durante mucho tiempo, el Parque del Xingú jugó un papel ideológico fundamental. Los indígenas del Xingú fueron siempre los más fotografiados, filmados y visitados por todos los indígenas brasileños; destacan en los libros ilustrados para turistas sobre el Brasil exótico, en las postales y en los estereotipos de los medios de comunicación. Así, la "protección" otorgada a los indígenas del Xingú -la garantía federal del derecho a la autodeterminación y propiedad de sus tierras- sirve como coartada, encubriendo la miseria y el saqueo sufrido por otros indios brasileños. Si esto ayudó a los indígenas del Xingú, después de todo, es mejor ser visitado por el rey de Bélgica y fotografiado por turistas japoneses que ser asesinado por un agricultor o que una empresa minera multinacional expropie su tierra, sin embargo, dio una imagen distorsionada de la situación real de los indígenas (Viveiros de Castro citado en Sterzi, 2019, p. 8). ${ }^{2}$

A partir de los años setenta, en un contexto de giro interpretativo que empieza a cuestionar el lugar del narrador (en este caso, del antropólogo), nuevas representaciones empiezan a surgir. Se asume así que no hay realismo, sino relativismo. Como comenta Naranjo (2020):

El desarrollo de la antropología visual, el auge de los estudios culturales y postcoloniales hizo que la fotografía adquiriese importancia en los debates de la esfera artística y científica en un momento en el que las teorías sobre la posmodernidad estaban muy presentes. Fue un momento intenso, marcado por la ruptura de la idea de progreso, de la modernidad, de la autocrítica que llevó al cuestionamiento de los métodos y de los discursos que habían utilizado los antropólogos durante el periodo colonial, en los que el eurocentrismo y la occidentalización habían estigmatizado o excluido a los locales.

Esta cuestión proporciona el desarrollo de una fotografía más libre de su iconicidad y permite trabajos como el de la fotógrafa inglesa Maureen Basilliat,

2 Traducción libre de la autora de: "Por muito tempo, o Parque do Xingu desempenhou um papel ideológico fundamental. Os índios do Xingu foram sempre os mais fotografados, filmados e visitados de todos os índios brasileiros; eles são conspícuos em livros ilustrados para turistas sobre o exótico Brasil, em cartões postais e nos estereótipos dos meios de comunicação de massa. Assim, a 'proteção' dada aos índios do Xingu - a garantia federal do direito à auto- determinação e à posse de suas terras - serve como um álibi, encobrindo a miséria e a pilhagem sofridas por outros índios brasileiros. Se isso ajudou os índios do Xingu - depois de tudo, é melhor ser visitado pelo rei da Bélgica e fotografado por turistas japoneses do que ser assassinado por um fazendeiro ou ter sua terra expropriada por uma companhia mineradora multinacional -, não obstante deu uma imagem distorcida da real situação dos índios" (Viveiros de Castro citado en Sterzi, 2019, p. $8)$. 
que, invitada por los Villas-Boas, desarrolla una obra fotográfica sobre comunidades indígenas del Xingú muy distinta de lo que se solía hacer hasta entonces. Sus fotografías asumen el papel subjetivo y creativo de la fotógrafa, al encuadrar de forma más dramática los rituales indígenas e impulsar una fotografía de cuño antropológico más poética.

Muy diferente de los tipos indígenas representados en la fotografía colonial, la fotografía de Basilliat tiene un interés especial en representar la vida en el Alto del Xingú; especialmente, los rituales. Esta acción busca disminuir las diferencias entre las dos culturas y ofrecer una mirada más cómplice de su existencia.

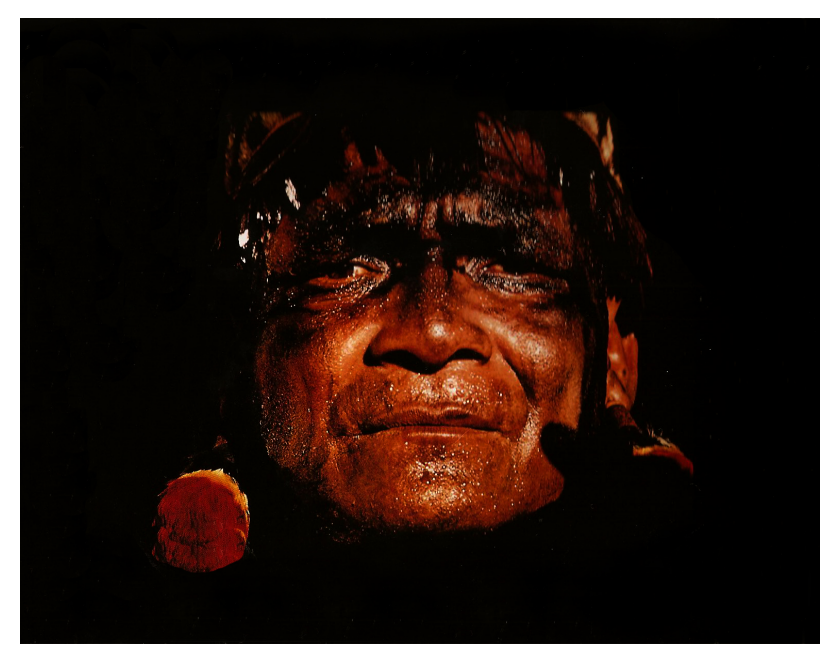

F3. Maureen Bisilliat. Sariruá após a Festa do Javari (1975), c. Parque Indígena do Xingu, MT Acervo Instituto Moreira Salles.

Con la representación se establece una experiencia, una construcción más fenomenológica de la fotografía que asume la mirada autoral, aunque no deja de ser una representación externa, eurocéntrica. Un ejemplar es el trabajo de Claudia Andujar, de origen polonesa, que crea un ensayo muy sensible sobre la cosmovisión de los Yanomami. Sus fotografías ofrecen una oportunidad de "presenciar" la relación casi sagrada con la luz al apropiarse de la técnica fotográfica como elemento narrativo. Con este arte, se buscó representar la cosmovisión indígena y no un modo de ver al indígena.

Esta representación permite una mezcla entre el arte y la antropología. La ciencia reconoce el dedo que aprieta el gatillo de la cámara, el ojo que recorta el paisaje, el fotografiado que se siente observado y se relaciona con la cámara. Así, nuevas 
formas de representación surgen, como, por ejemplo, la de Mario Cravo Neto, fotógrafo brasileño, nacido en Salvador en Bahía en 1947.

Su obra, aunque no explícitamente etnográfica, está incluida en el círculo de la fotografía antropológica, y la representación sobre afrobrasileños dialoga con la iconografía de tipos raciales creada por los fotógrafos Christiano Júnior y Auguste Stahl en el siglo XIX. Como afirma Heeren (2015):

Las imágenes de Cravo Neto, afectivamente, reinventan el cuerpo negro, comprometiéndose con la tradición que habitualmente lo ha registrado, pero empujándolo, evocando su espectro, pero manipulando este poder afectivo para subvertirlo. Propone una nueva forma de mostrar y enmarcar su visualización. ${ }^{3}$

A partir de los años setenta, hay más libertad en apropiarse del lenguaje fotográfico para representar los cuerpos tanto indígenas como afrobrasileños, y muchos son usados como plataformas de reivindicación política y de reconocimiento.

Sin duda, la fotografía va abandonando su valor indicial para tornarse un referente simbólico con el que se puede construir mensajes más abiertos. Sin embargo, esta etapa no deja de representar aún una visión colonial. Es un desarrollo natural que se va estableciendo, pero que no se rompe totalmente. A partir de la fotografía más endógena, que surge con las experiencias de la antropología visual en dinámicas de foto-elicitación4, es cuando se puede empezar a hablar de una autorrepresentación.

Surgen organizaciones sociales y antropólogos que se dedican a dar visibilidad a la producción visual por parte de los propios grupos indígenas y afrodescendientes. Un ejemplo muy conocido es la organización Video nas Aldeias, creada en 1986 por el antropólogo franco-brasileño Vincent Carelli entre

3. Traducción libre de la autora de "Cravo Neto's images, affectively, re-invent the black body, by engaging the tradition that has usually registered it, but pushing against it, evoking its specter, but manipulating this affective power to subvert it. It proposes a new way to show and frame its viewing." (Heeren, 2015).

4. La foto-elicitación se entiende aquí como metodología de investigación científica que utiliza las fotografías de los entrevistados/investigados como fuentes de datos, a través de las cuales se pueden analizar aspectos diversos. 
los Nambiquara, para equiparlos con equipos de cámaras para el registro y la expresión de sus visiones, principalmente en el formato vídeo.
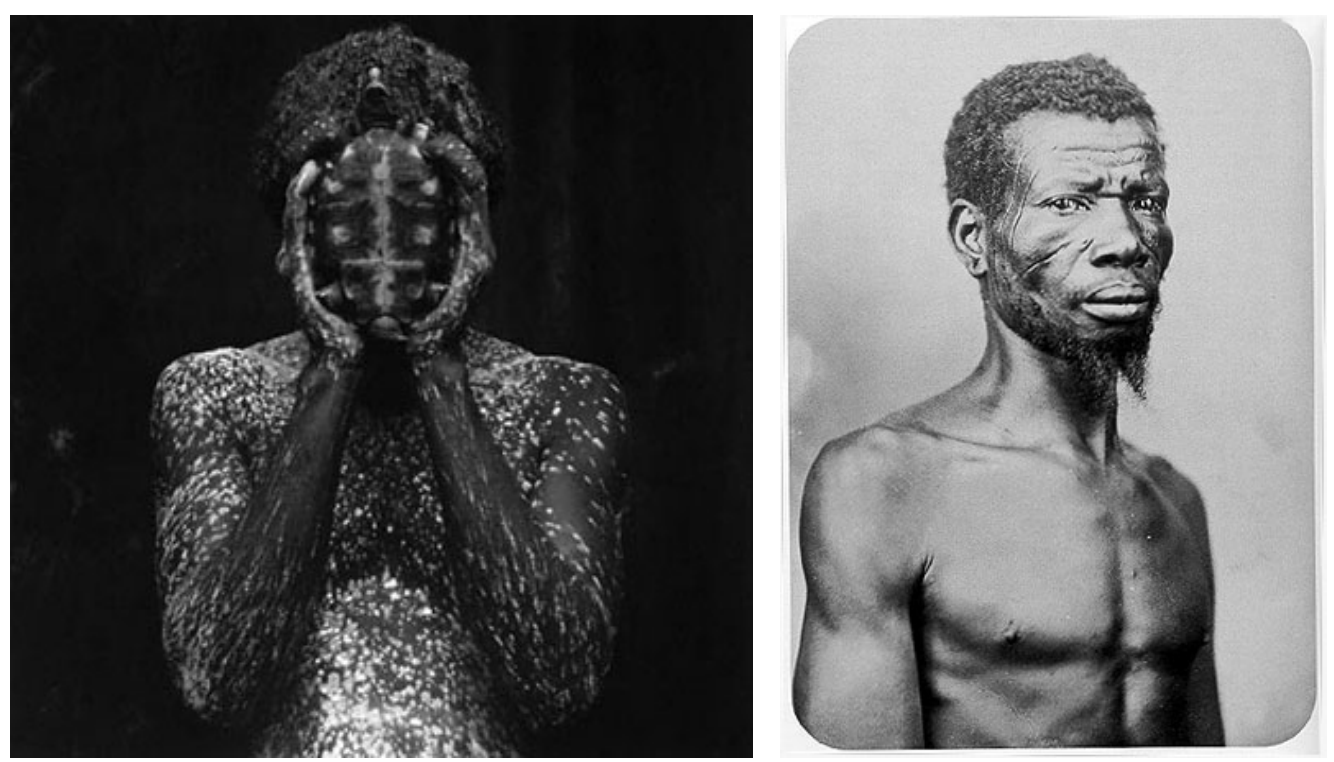

F4. Comparativa entre fotografías de Mário Cravo Neto y Auguste Stahl. Foto izquierda: Dues Da Cabeca, 1988. Mario Cravo Neto. Acervo Instituto Moreira Salles. Foto derecha: Escravo com escarificações no rosto, 1864. Auguste Stahl. Acervo Instituto Moreira Salles.

Entre los grupos afrodescendientes -principalmente, los que habitan las periferias urbanas-, diversas iniciativas se constituyeron como espacios de creación fotográfica, como, por ejemplo, el proyecto Nosso Olhar - Nós do Morro, en Rio de Janeiro, con grupos de personas que habitan las chabolas de la ciudad. Este movimiento de autorrepresentación se multiplicó por el país, con festivales audiovisuales o de fotografía para dar destaque a estos trabajos. Actualmente destacan más los colectivos de fotógrafos brasileños afrodescendientes que buscan diferenciarse por ocupar espacios antes limitados, con trabajos más autorales, como el grupo Afrotometria. El desarrollo de estos colectivos es un avance en esta representatividad, ya que, en este caso, mejor equipados y organizados, ocupan los espacios de visibilidad por propia iniciativa. Pero esta nueva práctica ofrece diversas cuestiones nuevas sobre lo que hemos analizado anteriormente con respeto de la descolonización. Estas prácticas están todavía muy desligadas de una reflexión propia sobre la autorrepresentación y siguen los cánones de la fotografía eurocéntrica. Muchas de estas fotografías, por 
ejemplo, representan modos de mirar renacentistas aprendidos desde la noción de perspectiva y otros fundamentos de la pintura.

Se hace necesario avanzar en las posibilidades de elaborar una estética fotográfica indígena o afrodescendiente que sea original, propia. Pero la historia tiene un peso significativo en la manera de percibir, pues la fotografía es un instrumento por sí colonial, que ha colaborado para crear la visión occidental y moderna sobre el mundo.

Hay alternativas que se vislumbran en algunas dinámicas de revisión histórica. Es esta lectura crítica la que destaca en la actualidad, donde estudios sobre la descolonización se multiplican y nos empujan a la restitución de la memoria, de cura y de reformulación simbólica de estas representaciones realizadas. Más que buscar una nueva forma de representar, lo que interesa es revisar el pasado, a partir de los propios grupos violados por el proceso colonial, para establecer una nueva relación con la imagen. Estas grietas pueden ser amalgamas si se establece un proceso de relectura y transformación.

Estas son estrategias que buscan comprender la historia y deconstruir las fantasías coloniales. En este sentido surgen nuevas iniciativas, en gran parte de fotógrafos y fotógrafas que buscan conectarse con sus historias a partir de un trabajo de investigación archivística y de apropiación. Sin duda, un referente importante es el fotógrafo Eustáquio Neves, nacido en 1955 en la ciudad de Juatuba, en el interior del estado de Minas Gerais (Brasil). En sus obras, el pasado se mezcla con el presente a partir de recursos artísticos como la pintura, la fotografía y el collage. Rigat:

la serie "Arturos" (1993-1996) genera imágenes emulsionadas que crean una estética onírica a partir de diferentes escenas de la comunidad Arturos (Contagem, Minas Gerais) buscando resaltar la identidad étnico-racial, el pasado colonial y la esclavitud, desde sus continuidades en el presente en el que se mantienen vivos su representación simbólica, su ritual religioso y sus lazos con África (Rigat, 2018, p. 242).

Otras iniciativas surgen con el fomento de instituciones del ámbito cultural, como, por ejemplo, el Instituto Moreira Salles, a partir de seminarios y becas de creación fotográfica que promueven estas nuevas lecturas, como el trabajo de la 
fotógrafa Aline Motta, que relaciona las experiencias familiares con la historia colonial brasileña. En estas nuevas prácticas, se perciben también obras sobre los movimientos transatlánticos, en el caso de los afrodescendientes, que buscan rescatar la historia de la diáspora africana.

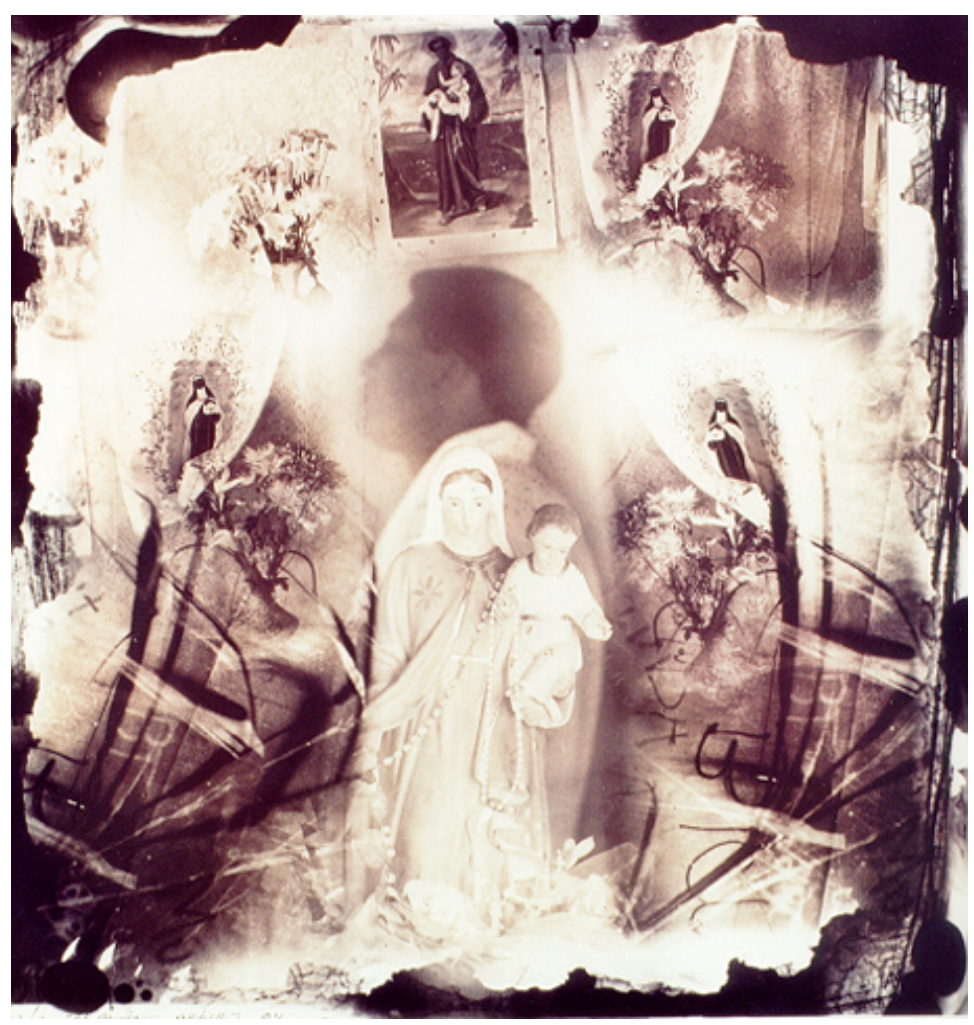

F5. Sem título. Eustáquio Neves. Serie Arturos. Contagem, 1994

Pero estas transformaciones siempre encuentran resistencia dentro del universo colonial. Con Internet, los algoritmos han creado sistemas privilegiados de visibilidad que vuelven a traicionar la lucha por la descolonización. En el momento actual, con las redes sociales, las deep fake y el big data, es aún más complicado revertir este aparato simbólico histórico persuasivo sobre la alteridad. Los algoritmos reproducen esta forma de dominio a partir de asociaciones, posicionamiento en las páginas de búsqueda, redes sociales, banco de imágenes, entre otros.

Las dinámicas de poder existentes se reproducen en herramientas digitales que se proponen ser "disruptivas" (Adner, 2002) perpetuando viejas ideologías y representaciones, además de descuidar nuevas narrativas y demandas sociales 
contemporáneas, como si fuera posible posicionar el ciberespacio como un espacio de trascendencia raza, clase y género (Carrera \& Carvalho, 2020). 5

\section{Conclusiones}

Con este estudio, se ha buscado analizar a partir de una perspectiva histórica la representación de indígenas y afrodescendientes en la fotografía antropológica de Brasil con el objetivo de investigar el discurso colonial que ha marcado la vivencia de los grupos sociales étnicos en el país y ha contribuido a la diferenciación racial que hoy marca la sociedad brasileña.

Esta revisión ha optado por una selección de obras y fotógrafos emblemáticos para este análisis, y deja de citar excepciones que en su época han desarrollado lenguajes y discursos alternativos. Pero hemos buscado ejemplos de estilos asociados a miradas específicas de cada momento, influenciados por los paradigmas epistemológicos que han evolucionado desde el inicio de la fotografía y de la antropología. Es cierto que es un trabajo de pinza en una iconografía tan vasta, pero asumimos estas obras como parte de un muestreo de estudio.

Se interpreta a partir de esta perspectiva una evolución en cinco fases de la representación de indígenas y afrodescendientes en la fotografía antropológica de Brasil. Las etapas propuestas, aunque no se sustituyen de manera abrupta entre estas, sí pueden ser diferenciadas a partir de una prismática más amplia evolutiva. La primera hemos visto que se refiere a la antropología física y una fotografía claramente colonial, marcada por la clasificación de las razas por sus trazos físicos. Sobre la segunda fase de esta evolución, a que la denominamos aquí como "Unitario", la cual podríamos ubicar en las primeras décadas del siglo $\mathrm{XX}$, la representación se refiere a la necesidad de construcción de la idea de nación, en que se busca crear un discurso de democracia racial y Estado. Con los grupos indígenas, a partir de las expediciones, con el intuito de domesticación.

5. Traducción libre de la autora de: as dinâmicas de poder existentes são reproduzidas em ferramentas digitais que se propõem "disruptivas" (Adner, 2002) perpetuando antigas ideologias e representações, além de negligenciar novas narrativas e demandas sociais contemporâneas, como se fosse possível posicionar o ciberespaço como um espaço para a transcendência da raça, da classe e do gênero (Carrera \& Carvalho, 2020). 
Con las comunidades afrodescendientes, a partir de imágenes de integración asociadas al discurso de democracia racial. También es importante comentar una tercera fase, que podríamos ubicarla a partir de los años cuarenta, con una diferenciación entre el etnográfico más científico al documental más creativo y de encantamiento, variando en el tiempo y en los estilos de fotógrafos y fotógrafas. La cuarta fase, de autorrepresentación, ha operado a finales de los años noventa y principio del siglo actual, influenciada por el "giro icónico" y la crisis de la representación, con el reconocimiento de integrar el fotografiado como coautor en la narrativa fotográfica antropológica. Ahora, en la quinta fase, se nota una participación más activa y organizada en la reflexión sobre la imagen, a partir de las relecturas de archivo y un documentalismo híbrido, que permite el diálogo con varias expresiones artísticas, no limitándose a la técnica y al aparato fotográfico.

Esta búsqueda por trazar una evolución histórica de la representación de indígenas y afrobrasileños con enfoque antropológico ha revelado la presencia abundante de fotógrafos extranjeros que han tomado relevo en los espacios de divulgación como son los museos y las editoras del país. Esto ya no se ve tan presente actualmente y se amplía la representatividad para fotógrafos y fotógrafas brasileñas.

Para no extendernos demasiado, no hemos hecho referencia al desarrollo tecnológico de la fotografía que ha contribuido en los cambios de representación, ya que la técnica es fundamental para la construcción del mensaje. Pero asumimos este aspecto como esencial. Desde el daguerrotipo que exigía cuerpos parados para una exposición correcta, a cámaras más ligeras con películas, pasando por las cámaras compactas y las digitales, que permiten más versatilidad en la fotografía de campo. También es importante recordar las cámaras embutidas en los teléfonos y las redes sociales, que han permitido una producción y difusión de imágenes más democrática. Ahora, con la digitalización de los acervos fotográficos, disponibles en Internet, los procesos de relectura también son más accesibles y comunitarios.

Para finalizar, cabe resaltar la posibilidad que tenemos en los tiempos actuales de asumir el rol en esta transformación al conectar el pasado con las 
reivindicaciones presentes y evitar que el racismo algorítmico se sobreponga a las luchas por la transformación simbólica necesarias para la descolonización.

\section{Referencias bibliográficas}

Azoulay, A. (2008). The Civil Contract of Photography. Nueva York: Zone Books. Azoulay, A. (2012). Civil Imagination. A Political Ontology of Photography. Nueva York: Verso.

Badillo, M. E. G. (2018). Los imaginarios femeninos a finales del siglo XVIII y sus representaciones visuales. Fuentes Humanísticas, año 30, (57), 47-63. Recuperado https://pdfs.semanticscholar.org/940f/e924116dfb80505609dbeaf51f66 511a8416.pdf

Batchen, G. (1999). Burning with Desire: The Conception of Photography. MIT Press.

Belting, H. (2007). Antropología de la imagen. Buenos Aires: Katz Editores.

Carrera, F. \& Carvalho, D. (2020). Algoritmos racistas: a hiper-ritualização da solidão da mulher negra em bancos de imagens digitais. Galáxia (São Paulo), (43), 99-114. doi: https://doi.org/10.1590/1982-25532020141614

Dahó, M. (2015). Fotografías en cuanto espacio público. Revista de Estudios Globales y Arte Contemporáneo, 3(1), 220-246. Recuperado de http://www.xavierribas.com/Contents/Texts/Texts/MDAHO_Fotografia s-Espacio-Publico.pdf

Dussel, E. (2018). La pólitica de la liberación. En Romero-Losacco, J., (compilador). Encuentros descoloniales (pp. 15-59). Caracas: Instituto Venezolano de Investigaciones Científicas (IVIC)/Fundación Editorial El $\begin{array}{lllll}\text { Perro } & y & \text { La } & \text { Rana. }\end{array}$ https://www.researchgate.net/profile/Jose_RomeroLosacco/publication/328697651_Encuentros_Descoloniales/links/5bdc 61d9a6fdcc3a8db89eof/Encuentros-Descoloniales.pdf

Flusser, V. (2014). Para uma filosofia de la fotografía. Buenos Aires: La Marca.

Fonseca, M., \& Jerrems, A. (2012). Pensamiento decolonial: ¿una "nueva" apuesta en las Relaciones Internacionales? Relaciones Internacionales, (19), 103-121. Recuperado de https://revistas.uam.es/relacionesinternacionales/article/view/5116/

García, J. (2005). Encuentro y desencuentros de los "saberes" en torno a la africanía "latinoamericana". En D. Mato, Cultura, política y sociedad Perspectivas latinoamericanas (pp. 359-377). Argentina: CLACSO, Consejo Latinoamericano de Ciencias Sociales, Ciudad Autónoma de Buenos Aires. Recuperado de http://bibliotecavirtual.clacso.org.ar/ar/libros/grupos/mato/Garcia.rtf 
Heeren, A. (2015). Specters of brazilian history in the early photographic work of Mario Cravo Neto. Artelogie, (7). doi: https://doi.org/10.4000/artelogie.1158

López Sanz, H. (2010). El escalpelo, la pluma y la cámara: imagen y objeto en la constitución de la etnología francesa. Tesis doctoral. Universidad de Valencia. Recuperado de https://core.ac.uk/download/pdf/71031414.pdf

Mitchell, W. J. T. (2003). Mostrando el ver: una crítica de la cultura visual. Estudios Visuales: Ensayo, teoría y crítica de la cultura visual y el arte contemporáneo, (1), 17-40.

Mitchell, W. J. T. (2009). Teoría de la Imagen. Ensayos sobre representación verbal y visual. Madrid: Akal.

Morel, M. (2001). Cinco imagens e múltiplos olhares:'descobertas' sobre os índios do Brasil e a fotografia do século XIX. História, Ciências, SaúdeManguinhos, 8, 1039-1058. doi: http://dx.doi.org/10.1590/So10459702001000500013

Naranjo, J. (2006). Fotografía, antropología y colonialismo (1845-2006). Barcelona: Gustavo Gili.

Naranjo, J. (2 de septiembre de 2020). Otras categorizaciones. Fotografía, antropología y descolonización cultural. $L U R$. Recuperado de https://elur.net/investigacion/otras-categorizaciones-fotografia-antropologia-ydescolonizacion-cultura

Pinney, C. (2016). Crisis and Visual Critique. Vis Anthropol Rev, (32), 73-78. doi: 10.1111/var.12094

Pinney, C. (1996). A História Paralela da Antropologia e da Fotografia. Antropologia e Fotografia. Cadernos de Antropologia e Imagem, pp. 2952.

Rigat, L. (2018) Fotografia latinoamericana contemporánea: critica poscolonial y renovación de los lenguajes. El caso Brasil. Crítica Cultural Palhoça, SC, 13(2), 233-244.

Romero-Losacco, J., Grosfoguel, R., Ochoa, K., Dussel, E., Bautista, J., \& Alimonda, H. (2018). Encuentros descoloniales. Caracas: Instituto Venezolano de Investigaciones Científicas (IVIC)/Fundación Editorial El Perro y La Rana.

Índio na Fotografia Brasileira (s.f.) Comissão Rondon. Pacificação, integração e nacionalismo. Recuperado de http://fotografia.povosindigenas.com.br/comissao-rondon/

Schwarcz, L. (2013). Escravos de Marc Ferrez. Recuperado de https://blogdoims.com.br/escravos-de-marc-ferrez-por-lilia-moritzschwarcz/

Shirey, H. (2017). Pierre Verger, Roger Bastide and A Cigarra: Candomblé, photography and anthropology in the popular press. Anthropology \& Photography,

(8).

Recuperado de 
http://www.therai.org.uk/images/stories/photography/AnthandPhoto Vol8.pdf

Schuster, S. y Buenaventura, A. (2017). Entre blanqueamiento y paraíso racial: el Imperio de Brasil y la legitimación visual de la esclavitud en las exposiciones universales. En: S. Schuster, H. Quiñones and Ó. Daniel, (Ed.), Imaginando América Latina: Historia y cultura visual, siglos XIXXXI, Editorial Universidad del Rosario.

Sterzi, E. (2019). Da fotografia como circum-navegação da antropologia. PORTO ARTE: Revista de Artes Visuais, 24(42). doi: https://doi.org/10.22456/2179-8001.98257

Tacca, F. D. (2011). O índio na fotografia brasileira: incursões sobre a imagem e o meio. História, Ciências, Saúde-Manguinhos, 18(1), 191-223. doi: http://dx.doi.org/10.1590/So104-59702011000100012

Tagg, J. (2005). El peso de la representación. Barcelona: Gustavo Gili.

Viveiros de Castro, E. (2011). Cara de índio - conversa com Eduardo Viveiros de Castro. Recuperado de https://blogdoims.com.br/cara-de-indioconversa-com-eduardo-viveiros-de-castro/ 